\title{
Serial assessment of the electrocardiographic strain pattern for prediction of new-onset heart failure during antihypertensive treatment: the LIFE study
}

\author{
Peter M. Okin ${ }^{1 *}$, Lasse Oikarinen ${ }^{2}$, Matti Viitasalo ${ }^{2}$, Lauri Toivonen ${ }^{2}$, \\ Sverre E. Kjeldsen ${ }^{3,4}$, Markku S. Nieminen ${ }^{2}$, Jonathan M. Edelman ${ }^{5}$, Björn Dahlöf6, \\ and Richard B. Devereux ${ }^{1}$ for the LIFE study Investigators
}

\begin{abstract}
${ }^{1}$ Greenberg Division of Cardiology, Weill Cornell Medical College, 525 East 68th Street, New York, NY 10065, USA; ${ }^{2}$ Division of Cardiology, Department of Medicine, Helsinki University Central Hospital, Helsinki, Finland; ${ }^{3}$ University of Oslo, Ullevål Hospital, Oslo, Norway; ${ }^{4}$ University of Michigan Medical Center, Ann Arbor, MI, USA; ${ }^{5}$ Merck \& Co., Inc., North Wales, PA, USA; and ${ }^{6}$ Department of Medicine, Sahlgrenska University Hospital/Östra, Gothenburg, Sweden
\end{abstract}

Received 16 September 2010; revised 11 October 2010; accepted 14 October 2010; online publish-ahead-of-print 14 January 2011

\begin{abstract}
Aims
Although the presence of the electrocardiographic (ECG) strain pattern has been associated with an increased risk of developing heart failure (HF), the relationship of regression vs. persistence vs. development of new ECG strain to subsequent HF is unclear.

Methods Electrocardiographic strain was evaluated at baseline and at year-1 in 7265 hypertensive patients without HF treated and results with atenolol- or losartan-based regimens. During $3.9 \pm 0.7$ years of follow-up after the year- 1 ECG, 154 patients (2.1\%) were hospitalized for HF. Five-year HF incidence was lowest in patients with no ECG strain (1.6\%), intermediate in patients with regression of strain (5.4\%), and highest in patients with persistent $(7.1 \%)$ or new strain $(7.0 \%$; $P<0.0001$ across groups). In the Cox multivariable analyses adjusting for the known predictive value of in-treatment ECG left ventricular hypertrophy by the Cornell product and Sokolow-Lyon voltage, in-treatment QRS duration, systolic and diastolic pressure, incident myocardial infarction and atrial fibrillation, randomized treatment and other risk factors for $\mathrm{HF}$, regression of strain [hazards ratio (HR) 2.4, 95\% confidence interval $(\mathrm{Cl}) 1.2-5.0$ ], persistence of strain (HR 1.9, 95\% Cl 1.2-3.2), and development of new ECG strain (HR 2.3, 95\% Cl 1.2-4.4) were all independently associated with an increased risk of new HF compared with the absence of ECG strain on both baseline and year-1 ECGs.

Conclusion

The development of new ECG strain or persistence of ECG strain between baseline and year-1 is associated with an increased risk of HF. The regression of ECG strain between baseline and year-1 does not convey a decreased risk of HF.

Clinical trials registration: http://clinicaltrials.gov/ct/show/NCT00338260.
\end{abstract}

Keywords

Electrocardiogram • Hypertension • Hypertrophy

\section{Introduction}

The classic strain pattern of lateral ST depression and T-wave inversion on the electrocardiogram (ECG) is a well-recognized marker of the presence and severity of anatomical left ventricular hypertrophy $(\mathrm{LVH}) .^{1-7}$ Electrocardiographic strain is associated with depressed LV function ${ }^{5}$ and improves ECG detection of structural hypertrophy when incorporated into scores that include standard voltage criteria. ${ }^{2,4}$ Electrocardiographic strain has been associated with adverse prognosis in a variety of populations, ${ }^{8-14}$

* Corresponding author. Tel: +1 212746 4688, Fax: +1 212746 8473, Email: pokin@med.cornell.edu

Published on behalf of the European Society of Cardiology. All rights reserved. (c) The Author 2011. For permissions please email: journals.permissions@oup.com. 
including hypertensive patients, ${ }^{8,9,12-14}$ and has often been the primary marker of untoward outcomes when ECG LVH criteria have been utilized for risk stratification. ${ }^{8,12,13}$ Indeed, strain on the baseline ECG was an independent predictor of cardiovascular (CV) morbidity and mortality ${ }^{9}$ and new-onset heart failure (HF $)^{14}$ among hypertensive patients with ECG LVH in the LIFE study.

The serial assessment of ECG voltage and voltage-duration product criteria for $\mathrm{LVH}$ has demonstrated that the regression of ECG LVH appears to confer a decreased risk of CV mortality and morbidity, including the development of new HF. ${ }^{11-13,15-18}$ Among LIFE study patients, ${ }^{18}$ a greater than median decrease in the Cornell product LVH was associated with a $36 \%$ lower adjusted risk of HF hospitalization, independent of treatment modality, blood pressure lowering, and other HF risk factors. The persistence or development of new ECG strain were strongly associated with an increased risk of CV morbidity and mortality in the LIFE study ${ }^{19}$ and with an increased risk of a composite CV endpoint that included new-onset HF in patients with essential hypertension. ${ }^{12}$ However, whether changes in the ECG strain pattern provide additional prognostic information for HF onset beyond that provided by changes in ECG LVH ${ }^{18}$ and QRS duration ${ }^{20}$ in the LIFE study population has not been examined. Therefore, the present study examined the relationship of the strain pattern on the baseline and year-1 ECGs in the LIFE study to the risk of HF hospitalization, independent of other HF risk factors, treatment effects, blood pressure reduction, and of the known effects of in-treatment QRS duration ${ }^{20}$ and regression of ECG LVH on HF incidence. ${ }^{18}$

\section{Methods}

\section{Subjects}

The LIFE study ${ }^{21,22}$ enrolled hypertensive patients with ECG LVH by the Cornell product ${ }^{23}$ and/or Sokolow-Lyon voltage criteria ${ }^{1}$ on a screening ECG in a prospective, double-blind study large enough $(n=9193)$ to demonstrate an appreciable reduction in mortality and morbid events with the use of losartan as opposed to atenolol. ${ }^{21}$ Eligible patients were men and women aged $55-80$ years with previously untreated or treated essential hypertension with mean blood pressure in the range $160-200 / 95-115 \mathrm{mmHg}$ after 1 and 2 weeks on placebo. A total of 7265 patients with no history of HF by patient self-report prior to enrolment or during the first year of treatment in LIFE had baseline and year-1 ECGs on which the strain pattern could be determined (3906 women and 3359 men, mean age $67 \pm 7$ years).

\section{Electrocardiography}

Hard-copy ECGs were interpreted at a core laboratory by experienced readers blinded to clinical information as previously reported in detail. ${ }^{5,9}$ QRS duration was measured to the nearest $4 \mathrm{~ms}$ in all 12 leads and R-wave amplitudes in leads aVL, V5, and V6 and S-wave amplitudes in leads $\mathrm{V} 1$ and $\mathrm{V} 3$ were measured to the nearest $0.5 \mathrm{~mm}(0.05 \mathrm{mV}){ }^{5,9,20}$ The product of QRS duration times the Cornell voltage combination $[\mathrm{RaVL}+\mathrm{SV} 3$, with $6 \mathrm{~mm}(0.6 \mathrm{mV})$ added in women] $>2440 \mathrm{~mm} \mathrm{~ms}^{5,22}$ or the Sokolow-Lyon voltage $(\mathrm{SV} 1+\mathrm{RV} 5 / 6)>38 \mathrm{~mm}^{1,22}$ was used to identify ECG LVH.

The determination of the presence or absence of ECG strain as a dichotomous variable was visually assessed on baseline and year-1 ECGs at Helsinki University Central Hospital as described previously. ${ }^{5,9}$ Repolarization abnormalities in leads V5 and/or V6 were considered consistent with the presence of typical strain when there was a down-sloping convex ST-segment with an inverted asymmetrical T-wave with polarity opposite to the main QRS deflection. ${ }^{5,9}$

\section{Endpoint determination}

Hospitalization for HF was a pre-specified secondary endpoint in the LIFE study. ${ }^{18,22}$ The diagnosis of HF was based on clinical and diagnostic findings modified from Framingham criteria ${ }^{24}$ that are outlined in Table 1. Each case was reviewed and verified by the Endpoint Committee, which was blinded to study ECG strain and LVH results when classifying possible morbid events. ${ }^{21,22}$

\section{Statistical methods}

Data management and analysis were performed with SPSS version 12.0 software. Data are presented as mean \pm SD for continuous variables and proportions for categorical variables. Patients were classified into four groups according to the presence or absence of strain at baseline and year-1 as follows: no strain on either ECG (absence of strain); strain at baseline but not at year-1 (regression of strain); strain on both ECGs (persistence of strain); or no strain at baseline and strain at year-1 (development of new strain). Differences in prevalences between groups were compared using $\chi^{2}$ analyses and mean values of continuous variables were compared using one-way ANOVA, with $P$-values given for the statistical significance of the linear trend across groups.

Event rates were calculated and plotted according to the KaplanMeier product limit method and statistical significance tested for the linear trend across groups using the log-rank statistic. The relation of strain at baseline and year-1 to the risk of developing new HF was assessed using Cox's proportional hazards models. Partial residuals were plotted against survival times and visually examined to check the proportional hazards assumption. To test the independence of serial assessment of ECG strain for incident HF, the presence or absence of ECG strain at baseline and year-1 was entered into a multivariable Cox model that also included as covariates age, gender, treatment group, race, diabetes, history of ischaemic heart disease, myocardial infarction, stroke, peripheral vascular disease, atrial fibrillation and smoking, baseline urinary albumin/creatinine ratio, total and HDL cholesterol, glucose, creatinine, uric acid, and body mass index as standard covariates, and baseline and in-treatment values of systolic and diastolic pressure, QRS duration, the Cornell product, the Sokolow-Lyon voltage, and incident myocardial infarction and atrial fibrillation as time-varying covariates.

Analyses were repeated stratifying the population by sex, age, race, treatment group, history of ischaemic heart disease, prevalent diabetes, and by the presence or absence of LVH by the Cornell product and Sokolow-Lyon voltage on the baseline ECG. The interaction between the presence or absence of strain at baseline and year-1 and these variables was formally tested by adding cross-product terms of strain and these variables into the models of the total population. For all tests, a two-tailed $P$-value of $<0.05$ was required for statistical significance.

\section{Statement of responsibility}

The authors had full access to and take full responsibility for the integrity of the data. All authors have read and agree to the manuscript as written. 
Table I Criteria for diagnosis of heart failure on hospitalization ${ }^{\mathrm{a}}$

\begin{tabular}{|c|c|}
\hline Major criteria & Minor criteria \\
\hline Clinical findings & Clinical findings \\
\hline Paroxysmal nocturnal dyspnoea & Night cough \\
\hline Jugular venous distension & Dyspnoea on ordinary exertion \\
\hline Pulmonary rales & Bilateral ankle oedema \\
\hline Ventricular $\mathrm{S}_{3}$ gallop & Hepatomegaly \\
\hline \multicolumn{2}{|l|}{ Hepatojugular reflux } \\
\hline \multicolumn{2}{|c|}{$\begin{array}{l}\text { Diuresis of } 10 \text { pounds or } 5 \mathrm{~kg} \text { in response to diuretic } \\
\text { treatment with clinical improvement in congestive symptoms }\end{array}$} \\
\hline Diagnostic findings & Diagnostic findings \\
\hline Chest X-ray & Chest X-ray \\
\hline Acute pulmonary oedema on chest X-ray & Pleural effusion or pulmonary vascular engorgement or redistribution \\
\hline Haemodynamic & Haemodynamic \\
\hline Pulmonary capillary wedge pressure $\geq 20 \mathrm{mmHg}$ & Pulmonary capillary wedge pressure of $16-19 \mathrm{mmHg}$ \\
\hline Left ventricular ejection fraction $\leq 35 \%$ & Left ventricular ejection fraction of $36-44 \%$ \\
\hline Cardiac index $<2.0 \mathrm{~L} / \mathrm{min}$ & Cardiac index of $2.0-2.4 \mathrm{~L} / \mathrm{min}$ \\
\hline Evidence of severe valvular heart disease & Evidence of moderate valvular heart disease \\
\hline \multicolumn{2}{|l|}{ Autopsy } \\
\hline Pulmonary oedema, visceral congestion or cardior & \\
\hline
\end{tabular}

${ }^{a}$ A definite diagnosis of heart failure required a minimum of: one major clinical plus one major diagnostic finding; or one major clinical plus two minor diagnostic findings; or one minor clinical plus two major or minor diagnostic criteria. Minor criteria were accepted only if they could not be attributed to another disease process. ${ }^{24}$

\section{Results}

Electrocardiographic strain was absent on both baseline and year-1 ECGs in 6236 patients (85.8\%), regressed from baseline to year-1 in 236 (3.2\%), persisted on both ECGs in 517 (7.1\%), and was absent at baseline but developed by year-1 in 276 patients (3.8\%). Clinical and demographic characteristics of patients in relation to the presence or absence of ECG strain at baseline and year-1 are shown in Table 2. Patients without strain on either ECG were younger, more likely to be female, less likely to be black, current smokers or have diabetes, a history of ischaemic heart disease, myocardial infarction, stroke, peripheral vascular disease or atrial fibrillation, had higher total and HDL cholesterol levels, less albuminuria, and lower serum glucose, creatinine, and uric acid levels.

Blood pressure and ECG LVH measurements at baseline and changes in these measurements between baseline and last in-study determination in relation to the presence or absence of ECG strain on baseline and year-1 ECGs are shown in Table 3. The absence of strain on both ECGs was associated with lower baseline systolic pressures, the Cornell product and SokolowLyon voltage, and with smaller reductions in systolic and diastolic pressure. The regression of strain between baseline and year-1 was associated with the greatest reductions in the Cornell product and Sokolow-Lyon voltage, whereas the development of new strain was associated with the smallest reductions in the Cornell product LVH during the course of the study.

During $3.9 \pm 0.7$ years of follow-up after the year-1 ECG, 154 patients $(2.1 \%)$ had a new HF hospitalization. The relationship of serial evaluation of ECG strain at baseline and year-1 to HF hospitalization is shown in Table 4 and Figure 1. Five-year incidence of hospitalization for HF was lowest in patients with no ECG strain (1.6\%), intermediate in patients with regression of strain $(5.4 \%)$, and highest in patients with persistent $(7.1 \%)$ or new strain $(7.0 \%$; $P<0.0001$ across groups). Strain on the baseline and/or year-1 ECG was associated with $39.6 \%$ (61 of 154) of new cases of HF, although strain was present in only $14.2 \%$ of the study population. In univariate Cox's analyses, the persistence of strain or development of a new ECG strain pattern was associated with the highest risk of developing HF, with 4.4- to 4.5-fold increased risks compared with the absence of strain on both ECGs, whereas patients with regression of strain between baseline and year-1 had a greater than three-fold increased risk of HF hospitalization.

Because patients who developed strain differed significantly from those who did not with respect to demographic and clinical variables which could affect outcome (Tables 1 and 2), the independent relation of new $\mathrm{HF}$ to the presence or absence of strain at baseline and year-1 was examined after adjusting for the possible effects of treatment, age, gender, race, prevalent diabetes, history of ischaemic heart disease, myocardial infarction, stroke, peripheral vascular disease, atrial fibrillation and smoking, baseline urinary albumin/creatinine ratio, total and HDL cholesterol, glucose, creatinine, uric acid, and body mass index and for the possible effects of baseline and in-treatment systolic and diastolic blood pressure, QRS duration, the Cornell product and Sokolow-Lyon voltage, and incident myocardial infarction and atrial fibrillation treated as time-dependent covariates (Table 4). After adjusting for these factors, the development of new ECG strain, persistence of strain, and regression of ECG strain were each associated with an approximately two-fold increased risk of HF hospitalization. Importantly, in-treatment ECG LVH by the Cornell product and Sokolow-Lyon voltage, treated as time-varying covariates, 
Table 2 Demographic and clinical characteristics in relation to the presence of electrocardiographic strain at baseline and year-1

\begin{tabular}{|c|c|c|c|c|c|}
\hline Variables & $\begin{array}{l}\text { Strain -/strain - } \\
(n=6236), \text { no } \\
\text { strain }\end{array}$ & $\begin{array}{l}\text { Strain }+/ \text { strain - } \\
(n=236), \\
\text { regression of strain }\end{array}$ & $\begin{array}{l}\text { Strain }+/ \text { strain }+ \\
(n=517), \\
\text { persistent strain }\end{array}$ & $\begin{array}{l}\text { Strain -/strain }+ \\
(n=276), \text { new } \\
\text { strain }\end{array}$ & $P$-value ${ }^{a}$ \\
\hline Age (years) & $66.3 \pm 7.0$ & $66.8 \pm 7.1$ & $67.9 \pm 6.8$ & $69.1 \pm 6.8$ & $<0.001$ \\
\hline Sex (\% female) & 55.8 & 38.1 & 38.3 & 49.3 & $<0.001$ \\
\hline Race (\% Black) & 4.2 & 9.3 & 15.3 & 8.0 & $<0.001$ \\
\hline Diabetes (\%) & 11.5 & 14.4 & 18.0 & 17.0 & $<0.001$ \\
\hline History of IHD (\%) & 11.3 & 26.3 & 30.9 & 22.8 & $<0.001$ \\
\hline History of MI (\%) & 3.9 & 8.9 & 13.5 & 10.4 & $<0.001$ \\
\hline History of stroke (\%) & 3.5 & 4.2 & 7.5 & 6.5 & $<0.001$ \\
\hline History of PVD (\%) & 4.8 & 7.6 & 8.9 & 8.0 & $<0.001$ \\
\hline History of AFib (\%) & 2.5 & 5.1 & 5.4 & 10.1 & $<0.001$ \\
\hline Current smoker (\%) & 15.0 & 20.8 & 17.6 & 26.1 & $<0.001$ \\
\hline Treatment with losartan (\%) & 50.6 & 53.8 & 48.2 & 41.7 & 0.014 \\
\hline Body mass index $\left(\mathrm{kg} / \mathrm{m}^{2}\right)$ & $28.1 \pm 4.7$ & $27.7 \pm 4.4$ & $27.7 \pm 4.9$ & $27.6 \pm 5.0$ & 0.134 \\
\hline Total cholesterol (mM) & $6.06 \pm 1.10$ & $5.89 \pm 1.18$ & $5.91 \pm 1.16$ & $5.98 \pm 1.14$ & 0.003 \\
\hline HDL cholesterol (mM) & $1.52 \pm 0.44$ & $1.41 \pm 0.37$ & $1.40 \pm 0.40$ & $1.41 \pm 0.40$ & $<0.001$ \\
\hline UACR (mg/mM) & $5.6 \pm 28.2$ & $8.0 \pm 18.8$ & $13.1 \pm 42.2$ & $12.9 \pm 32.0$ & $<0.001$ \\
\hline Glucose (mM) & $5.92 \pm 2.00$ & $6.26 \pm 2.34$ & $6.36 \pm 2.89$ & $6.30 \pm 2.50$ & $<0.001$ \\
\hline Creatinine $(\mu M)$ & $84.6 \pm 18.3$ & $94.3 \pm 24.9$ & $95.4 \pm 21.9$ & $91.7 \pm 20.2$ & $<0.001$ \\
\hline Uric acid (mg/mM) & $325 \pm 77$ & $350 \pm 77$ & $347 \pm 76$ & $338 \pm 76$ & $<0.001$ \\
\hline
\end{tabular}

AFib, atrial fibrillation; IHD, ischaemic heart disease; MI, myocardial infarction; PVD, peripheral vascular disease; UACR, urine albumin/creatinine ratio.

${ }^{a}$ Differences in prevalences between groups were compared using $\chi^{2}$ analyses and mean values of continuous variables were compared using ANOVA for linear trend.

Table 3 Baseline and change from baseline to last in-study measurement of blood pressure and electrocardiographic left ventricular hypertrophy in relation to the presence of electrocardiographic strain at baseline and year-1

\begin{tabular}{|c|c|c|c|c|c|}
\hline Variables & $\begin{array}{l}\text { Strain -/strain- } \\
(n=6236), \text { no } \\
\text { strain }\end{array}$ & $\begin{array}{l}\text { Strain }+/ \text { strain }- \\
(n=236), \text { regression } \\
\text { of strain }\end{array}$ & $\begin{array}{l}\text { Strain }+/ \text { strain }+ \\
(n=517), \text { persistent } \\
\text { strain }\end{array}$ & $\begin{array}{l}\text { Strain - /strain }+ \\
(n=276), \text { new } \\
\text { strain }\end{array}$ & $\begin{array}{l}P \text {-value for } \\
\text { linear trend }\end{array}$ \\
\hline \multicolumn{6}{|l|}{ Baseline measurements } \\
\hline Systolic BP (mmHg) & $173.9 \pm 14.4$ & $176.4 \pm 14.2$ & $176.9 \pm 14.8$ & $177.4 \pm 13.7$ & $<0.001$ \\
\hline Diastolic BP (mmHg) & $98.2 \pm 8.5$ & $97.6 \pm 9.8$ & $97.4 \pm 9.8$ & $97.8 \pm 9.6$ & 0.222 \\
\hline Cornell's product (mm ms) & $2618 \pm 717$ & $2932 \pm 961$ & $2923 \pm 913$ & $2853 \pm 925$ & $<0.001$ \\
\hline Sokolow-Lyon voltage $(\mathrm{mm})$ & $28.9 \pm 9.9$ & $35.0 \pm 10.5$ & $37.8 \pm 11.1$ & $33.6 \pm 10.9$ & $<0.001$ \\
\hline \multicolumn{6}{|c|}{ Change from baseline to last measurement } \\
\hline Systolic BP (mmHg) & $-29.8 \pm 19.3$ & $-32.0 \pm 20.0$ & $-32.1 \pm 18.9$ & $-32.7 \pm 21.2$ & 0.010 \\
\hline Diastolic BP (mmHg) & $-17.3 \pm 10.0$ & $-18.0 \pm 10.7$ & $-18.7 \pm 10.4$ & $-18.0 \pm 11.4$ & 0.017 \\
\hline Cornell's product (mm ms) & $-208 \pm 692$ & $-372 \pm 857$ & $-201 \pm 929$ & $-119 \pm 936$ & 0.001 \\
\hline Sokolow-Lyon voltage $(\mathrm{mm})$ & $-3.8 \pm 6.8$ & $-7.7 \pm 8.9$ & $-4.8 \pm 9.9$ & $-3.8 \pm 9.2$ & $<0.001$ \\
\hline
\end{tabular}

remained significant predictors of HF hospitalization in this multivariable Cox model (data not shown).

The predictive value of the presence or absence of ECG strain at baseline and year-1 for the development of new HF in relevant subsets of the population is examined in Table 5. The association between baseline and year-1 ECG strain and HF hospitalization was similar in men and women, blacks and other ethnicities, in both treatment arms of the study, in patients above and below 65 years of age, among patients with and without a history of ischaemic heart disease and with or without prevalent diabetes, and among patients with and without LVH on their baseline ECG by either the Cornell product or the Sokolow-Lyon voltage criteria, with non-significant interaction terms for these variables. 
Table 4 Five-year heart failure incidence, univariate and multivariable Cox's regression analyses to assess the relation of new heart failure to electrocardiographic strain at baseline and year-1

\begin{tabular}{|c|c|c|c|c|c|}
\hline Event & $\begin{array}{l}\text { Strain -/strain - } \\
(n=6236), \text { no } \\
\text { strain }\end{array}$ & $\begin{array}{l}\text { Strain }+/ \text { strain }- \\
(n=236), \text { regression of } \\
\text { strain }\end{array}$ & $\begin{array}{l}\text { Strain }+/ \text { strain }+ \\
(n=517), \text { persistent } \\
\text { strain }\end{array}$ & $\begin{array}{l}\text { Strain -/strain }+ \\
(n=276), \text { new } \\
\text { strain }\end{array}$ & $\begin{array}{l}P \text {-value for } \\
\text { linear trend }\end{array}$ \\
\hline \multicolumn{6}{|l|}{5 -year event rates (\%) } \\
\hline Heart failure incidence (\%) & 1.6 & 5.4 & 7.1 & 7.0 & $<0.0001$ \\
\hline \multicolumn{6}{|c|}{ Hazard ratios ( $95 \%$ confidence intervals) } \\
\hline Univariate Cox's model & 1 & $3.2(1.7-6.1)$ & $4.5(3.1-6.7)$ & $4.4(2.6-7.4)$ & $<0.001$ \\
\hline Multivariate Cox's model ${ }^{\mathrm{a}}$ & 1 & $2.4(1.2-5.0)$ & $1.9(1.2-3.2)$ & $2.3(1.2-4.4)$ & $<0.001$ \\
\hline
\end{tabular}

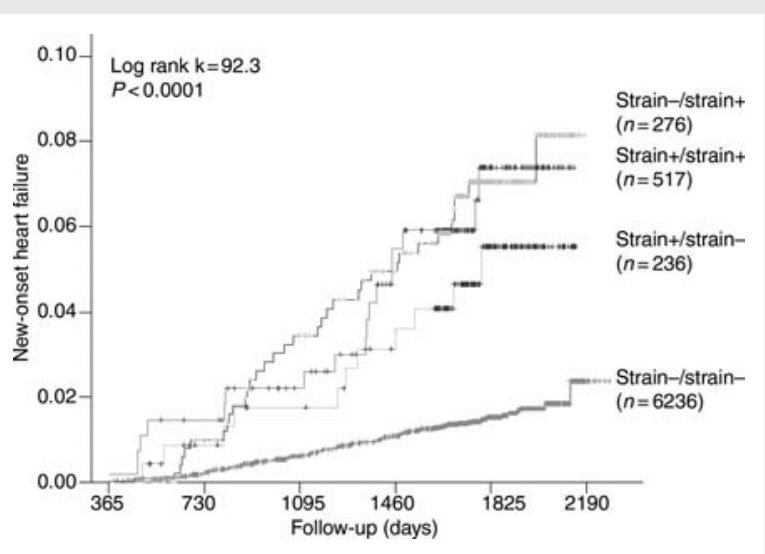

Figure I Kaplan-Meier curves comparing new-onset heart failure rates between patients according to the presence or absence of electrocardiographic strain on their baseline and year-1 electrocardiograms. ( $n=$ number of patients; strain-I strain - represents the absence of strain on baseline and year-1 electrocardiogram; strain $+/$ strain - represents the presence of strain on baseline electrocardiogram and the absence of strain on year-1 electrocardiogram, regression of strain; strain +1 strain + represents the presence of strain on baseline and year-1 electrocardiogram, persistence of strain; strain -/strain+ represents the absence of strain on baseline electrocardiogram and the presence of strain on year-1 electrocardiogram, development of new strain).

\section{Discussion}

This study demonstrates that the development of new ECG strain or persistence of ECG strain between baseline and year-1 during the LIFE study was associated with an increased risk of hospitalization for new HF and that the regression of ECG strain between baseline and year-1 does not convey a decreased risk of developing HF. The increased risk of HF associated with ECG strain at baseline and/or year-1 was independent of the previously demonstrated predictive values of in-treatment ECG LVH ${ }^{18}$ and QRS duration ${ }^{20}$ for new HF, of the baseline and in-treatment severity of hypertension, and persisted after adjusting for randomized treatment and the higher prevalence of other $\mathrm{CV}$ disorders and $\mathrm{HF}$ risk factors associated with ECG strain. These findings highlight the adverse prognostic value of ECG strain, even if not persistent between ECG evaluations, for new HF in hypertensive patients in the setting of substantial decreases in both systolic and diastolic pressure and suggest that more aggressive therapy may be warranted in hypertensive patients who have ECG strain to reduce the risk of developing new HF.

\section{Electrocardiographic strain and the prediction of heart failure}

Although the relationship of CV risk to the ECG strain pattern on a single ECG has been demonstrated in population-based studies and patients with hypertension, ${ }^{8-13}$ the relationship of ECG strain to new-onset HF has been less well characterized. ${ }^{8,13,14}$ Verdecchia et al. ${ }^{8}$ found strain on a baseline ECG to be associated with a greater than two-fold increased risk of a composite $\mathrm{CV}$ endpoint that included a small number of hospitalizations for new HF in 1717 hypertensive subjects, but did not separately examine the predictive value of ECG strain for new HF. Similarly, among over 28000 patients enrolled in either ONTARGET or TRANSCEND, ${ }^{13}$ baseline strain alone was associated with a 1.7-fold increased risk and strain in combination with ECG LVH by modified Cornell's voltage criteria with a 2.2-fold increased risk of a composite CV endpoint which included the development of new HF. However, the predictive value of ECG strain for new HF alone was not reported. ${ }^{13}$ In contrast, previous evaluation in the LIFE study ${ }^{14}$ revealed that strain on a baseline ECG was an independent predictor of new-onset $\mathrm{HF}$ and was associated with a $70 \%$ increased risk of developing HF. However, these studies did not examine the relationship of ECG strain over time to CV outcomes or the development of new HF.

The relationship of the presence or absence of ECG strain over time to CV outcomes has not been extensively evaluated ${ }^{11,12,19}$ and no previous study has examined the predictive value of serial evaluation of ECG strain for new HF. In contrast, the present study demonstrates that the development of new strain, persistence of strain, and regression of ECG strain between 
Table 5 Cox's analyses to assess the predictive value of electrocardiographic strain at baseline and year-1 for new-onset heart failure in relevant subgroups of the study population

\begin{tabular}{|c|c|c|c|c|c|c|}
\hline Subgroup & $\begin{array}{l}\text { HF } \\
(n)\end{array}$ & $\begin{array}{l}\text { Strain -/strain - } \\
(n=6236), \text { no } \\
\text { strain }\end{array}$ & $\begin{array}{l}\text { Strain }+/ \text { strain - } \\
(n=236), \\
\text { regression of strain }\end{array}$ & $\begin{array}{l}\text { Strain }+/ \text { strain }+ \\
(n=517), \\
\text { persistent strain }\end{array}$ & $\begin{array}{l}\text { Strain - /strain + } \\
(n=276), \text { new } \\
\text { strain }\end{array}$ & $\begin{array}{l}P \text {-value for } \\
\text { interaction }\end{array}$ \\
\hline \multicolumn{7}{|l|}{ Sex } \\
\hline Male $(n=3359)$ & 77 & 1 & $1.7(0.6-4.8)$ & $4.4(2.6-7.4)$ & $3.8(1.8-8.0)$ & 0.286 \\
\hline Female $(n=3906)$ & 77 & 1 & $6.0(2.7-13.2)$ & $4.5(2.4-8.4)$ & $5.0(2.4-10.1)$ & \\
\hline \multicolumn{7}{|l|}{ Race } \\
\hline White or other $(n=6877)$ & 136 & 1 & $2.3(1.1-5.1)$ & $4.7(3.1-7.2)$ & $4.3(2.5-7.5)$ & 0.167 \\
\hline Black $(n=388)$ & 18 & 1 & $6.8(2.0-23.3)$ & $2.4(0.7-7.4)$ & $3.5(0.7-16.7)$ & \\
\hline \multicolumn{7}{|l|}{ Treatment } \\
\hline Atenolol $(n=3617)$ & 78 & 1 & $1.9(0.6-6.1)$ & $4.6(2.6-8.0)$ & $5.9(3.2-11.0)$ & 0.261 \\
\hline Losartan $(n=3648)$ & 76 & 1 & $4.4(2.1-9.4)$ & $4.5(2.6-8.0)$ & $2.4(0.9-6.7)$ & \\
\hline \multicolumn{7}{|l|}{ Age (years) } \\
\hline Less than $65(n=2902)$ & 37 & 1 & $2.2(0.5-9.5)$ & $6.2(2.9-13.4)$ & $5.0(1.5-16.7)$ & 0.626 \\
\hline 65 or greater $(n=4363)$ & 117 & 1 & $3.7(1.8-7.4)$ & $3.9(2.4-6.2)$ & $3.8(2.1-6.7)$ & \\
\hline \multicolumn{7}{|l|}{ History of IHD } \\
\hline No $(n=6277)$ & 100 & 1 & $4.0(1.9-8.4)$ & $3.5(2.0-6.2)$ & $5.5(3.1-10.1)$ & 0.104 \\
\hline Yes $(n=988)$ & 54 & 1 & $1.2(0.4-4.1)$ & $3.2(1.8-5.7)$ & $1.6(0.6-4.7)$ & \\
\hline \multicolumn{7}{|l|}{ Diabetes } \\
\hline No $(n=6373)$ & 110 & 1 & $3.6(1.7-7.5)$ & $5.9(3.7-9.2)$ & $4.8(2.6-9.0)$ & 0.082 \\
\hline Yes $(n=892)$ & 44 & 1 & $2.2(0.7-7.1)$ & $1.6(0.7-3.9)$ & $2.7(1.1-7.1)$ & \\
\hline \multicolumn{7}{|l|}{ CP LVH } \\
\hline No $(n=2583)$ & 41 & 1 & $2.4(0.6-10.2)$ & $4.2(1.7-10.1)$ & $6.5(2.7-15.9)$ & 0.682 \\
\hline Yes $(n=4682)$ & 113 & 1 & $3.4(1.7-6.8)$ & $4.4(2.8-6.9)$ & $3.6(1.9-6.8)$ & \\
\hline \multicolumn{7}{|l|}{ SL LVH } \\
\hline No $(n=5712)$ & 103 & 1 & $3.9(1.8-8.5)$ & $5.5(3.3-9.3)$ & $5.0(2.7-9.3)$ & 0.233 \\
\hline Yes $(n=1553)$ & 51 & 1 & $1.9(0.7-5.3)$ & $2.5(1.3-4.8)$ & $2.8(1.1-7.3)$ & \\
\hline
\end{tabular}

CP, Cornell product; HF, heart failure; IHD, ischaemic heart disease; SL, Sokolow-Lyon voltage.

baseline and year-1 were associated with an increased risk of new $\mathrm{HF}$, independent of the possible impact of standard CV risk factors, randomized treatment assignment, baseline and in-treatment diastolic and systolic blood pressure, and of the previously demonstrated prognostic value of in-treatment ECG LVH and QRS duration for new HF in this population. ${ }^{18,20}$ In addition, the association of baseline and year- 1 strain and new HF was similar in all relevant subsets of the population. Furthermore, similar to the predictive value of baseline and year-1 strain for CV morbidity and mortality in the LIFE study population, ${ }^{19}$ the regression of ECG LVH by the Cornell product and Sokolow-Lyon voltage retained the predictive value for new HF outcomes in the current study when the serial assessment of ECG strain is taken into account, emphasizing the need for the serial assessment of both standard ECG LVH criteria and lateral repolarization abnormalities to accurately assess changing risk over time in the hypertensive population.

Although the precise mechanisms linking the development of ECG strain to the development of HF are not known, the strong association of strain with abnormalities of CV structure and function may in part explain the adverse prognosis associated with strain. In the present study, patients with new or persistent strain were older, had higher prevalences of diabetes, history of various forms of heart and vascular disease, and evidence of greater end-organ damage as manifested by albuminuria. In addition, patients who developed new ECG strain had the least regression of ECG LVH by the Cornell product criteria, suggesting less improvement in LVH despite similar reductions in blood pressure in this group. However, new ECG strain remained predictive of outcomes in the current study after adjusting for the possible impact of these factors. In the echocardiographic substudy of LIFE $^{5}$ and a cross-sectional study of 440 patients with resistant hypertension, ${ }^{7}$ baseline ECG strain was strongly related to the presence of coronary heart disease, increased LV mass, and echocardiographic LVH that was more likely to be concentric, factors that predispose to increased CV risk. Further analysis of baseline LV mass and function in relation to both baseline and year-1 ECG strain in the echocardiographic substudy of LIFE ${ }^{5}$ demonstrated that baseline LV mass index was highest and LV midwall shortening was lowest and most likely to be abnormal in patients with persistent or new ECG strain and that baseline LV mass was also elevated in patients with regression of strain between baseline and year-1. The absence of a significant association between baseline ECG strain and echocardiographic measures of 
diastolic dysfunction ${ }^{25}$ further suggests that the predictive value of ECG strain for new HF may be mediated via abnormalities of LV systolic function. However, the small number of incident HF cases among the 770 patients in the LIFE echocardiography substudy who were included in the present study $(n=12)$ precludes meaningful analysis of the relationship of LV systolic or diastolic function to new-onset HF in this population. This problem and the strong association of hypertension with impaired LV diastolic function in a recent population-based study ${ }^{26}$ suggests that further evaluation of the relationship of ECG strain to the development of LV systolic and diastolic dysfunction and HF will be necessary. In addition to the possible relation of ECG strain to coronary heart disease and LV mass, ${ }^{5,7}$ ST depression and T-wave inversion may reflect true subendocardial ischaemia in the absence of coronary disease, because of hypertrophy-induced compensatory increases in coronary artery diameter that are inadequate for the magnitude of increased LV mass and wall thickness. ${ }^{27-29}$ This concept is supported by the association of ECG strain with increased wall stress-mass-heart rate product among hypertensive patients with ECG LVH but no evidence of coronary disease in the LIFE study, ${ }^{5}$ providing evidence of a demand-side predisposition to myocardial ischaemia in these patients.

\section{Study limitations and perspectives}

The independent relation of the presence of ECG strain at baseline and/or year-1 to increased risk of HF in LIFE despite aggressive blood pressure reduction suggests that the presence or development of new strain on the ECG may be used to identify hypertensive patients with ECG LVH who require more aggressive antihypertensive therapy aimed at further reducing HF risk in these patients. However, there are several potential limitations of our study that warrant review. First, the use of hospitalization for HF to define incident HF most certainly underestimates the true incidence of $\mathrm{HF}$, potentially reducing precision of the estimates of the relationship of ECG strain changes to HF incidence. Secondly, the relatively small number of cases of HF associated with strain potentially limits the ability to differentiate the impact between old and new strain on HF incidence. Thirdly, although it would be of interest to examine changes in LV structure and function according to changes in ECG strain and the development of new HF, the small number of incident HF cases in the echocardiographic substudy of LIFE precludes meaningful analyses along these lines. Fourthly, the inferences that may be drawn from the present study are potentially limited by the lack of ECG strain data on ECGs obtained after year- 1 and by the absence of quantitative data assessing the degree of ST depression in this population. Previous observations that the magnitude of ST depression in the lateral leads is strongly related to the presence and severity of $\mathrm{LVH}^{6}$ and that measured ST depression and echocardiographic LV mass provide complimentary prognostic information ${ }^{30}$ suggest that the serial assessment of the magnitude of lateral repolarization abnormality may provide additional prognostic benefit in hypertensive patients. Further study will be necessary to address this important question. Finally, given that a clinical diagnosis of HF in the community is commonly based, at least in part, on findings on the $E C G,{ }^{31}$ the current findings suggest that the serial evaluation of the presence of strain on the ECG may increase the utility of the ECG in detecting new-onset HF.

\section{Funding}

Supported in part by grant COZ-368 and an Investigator Initiated Study Proposal Grant from Merck \& Co., Inc., West Point, PA, USA.

Conflict of interest: S.E.K. receives honoraria from Merck \& Co., Inc., Astra-Zeneca, Bayer, Boehringer-Ingelheim, Novartis, Pfizer, Sanofi, Sankyo, and Menarini. J.M.E. is employed by and owns stock in Merck \& Co., Inc. B.D. receives honoraria from Merck \& Co., Inc., Novartis, and Boehringer-Ingelheim and serves as a consultant for Novartis, Boehringer-Ingelheim, and Daiichi-Sankyo. R.B.D. receives honoraria from Merck \& Co., Inc. and serves on advisory boards for Merck \& Co., Inc., Novartis, and Novo-Nordisk.

\section{References}

1. Sokolow M, Lyon TP. The ventricular complex in left ventricular hypertrophy as obtained by unipolar precordial and limb leads. Am Heart J 1949;37:161-186.

2. Romhilt DW, Estes EH. A point-score system for the ECG diagnosis of left ventricular hypertrophy. Am Heart J 1968;75:752-759.

3. Levy D, Labib SB, Andersen KM, Christiansen JC, Kannel WB, Castelli WP. Determinants of sensitivity and specificity of electrocardiographic criteria for left ventricular hypertrophy. Circulation 1990;81:815-820.

4. Schillaci G, Verdecchia P, Borgioni C, Ciucci A, Guerrieri M, Zampi I, Battistelli M, Bartoccini C, Porecellata C. Improved electrocardiographic diagnosis of echocardiographic left ventricular hypertrophy. Am J Cardiol 1994;74:714-719.

5. Okin PM, Devereux RB, Nieminen MS, Jern S, Oikarinen L, Viitasalo M, Toivonen L, Kjeldsen SE, Julius S, Dahlöf B. Relationship of the electrocardiographic strain pattern to left ventricular structure and function in hypertensive patients: The LIFE Study. J Am Coll Cardiol 2001;38:514-520.

6. Okin PM, Devereux RB, Fabsitz RR, Lee ET, Galloway JM, Howard BV. Quantitative assessment of electrocardiographic left ventricular strain predicts increased left ventricular mass: The Strong Heart Study. J Am Coll Cardiol 2002;40: 1395-1400.

7. Salles G, Cardoso C, Nogueira AR, Bloch K, Muxfeldt E. Importance of the electrocardiographic strain pattern in patients with resistant hypertension. Hypertension 2006;48:437-442.

8. Verdecchia P, Schillaci G, Borgioni C, Ciucci A, Gattobigio R, Zampi I, Porcellati C. Prognostic value of a new electrocardiographic method for diagnosis of left ventricular hypertrophy. J Am Coll Cardiol 1998;31:383-390.

9. Okin PM, Devereux RB, Nieminen MS, Jern S, Oikarinen L, Viitasalo M, Toivonen L, Kjeldsen SE, Julius S, Snapinn S, Dahlöf B. Electrocardiographic strain pattern and prediction of cardiovascular morbidity and mortality in hypertensive patients. Hypertension 2004;44:48-54.

10. Hsieh BP, Pham MX, Froelicher VF. Prognostic value of electrocardiographic criteria for left ventricular hypertrophy. Am Heart J 2005;150:161-167.

11. Levy D, Salomon M, D’Agostino RB, Belanger AJ, Kannel WB. Prognostic implications of baseline electrocardiographic features and their serial changes in subjects with left ventricular hypertrophy. Circulation 1994;90:1786-1793.

12. Verdecchia P, Reboldi G, Angeli F, Avanzini F, de Simone G, Pede S, Perticone F, Schillaci G, Vanuzzo D, Maggioni AP on behalf of the HEART Survey Study Group. Prognostic value of serial electrocardiographic voltage and repolarization changes in essential hypertension: The HEART Survey Study. Am J Hypertens 2007; 20:997-1004.

13. Verdecchia P, Sleight P, Mancia G, Fagard R, Trimarco B, Schmieder RE, Kim J-H, Jennings G, Jansky P, Chen J-H, Liu L, Gao P, Probstfield J, Teo K, Yusuf S, for the ONTARGET/TRANSCEND Investigators. Effects of telmisartan, ramipril, and their combination on left ventricular hypertrophy in individuals at high vascular risk in the ongoing telmisartan alone and in combination with ramipril global end point trial and the telmisartan randomized assessment study in ACE intolerant subjects with cardiovascular disease. Circulation 2009;120:1380-1389.

14. Okin PM, Devereux RB, Nieminen MS, Jern S, Oikarinen L, Viitasalo M, Toivonen L, Kjeldsen SE, Dahlöf B, for the LIFE Study Investigators. Electrocardiographic strain pattern and prediction of new-onset congestive heart failure in hypertensive patients: The LIFE Study. Circulation 2006;113:67-73.

15. Mathew J, Sleight P, Lonn E, Johnstone D, Pogue J, Yi Q, Bosch J, Sussex B, Probstfield J, Yusuf S, Heart Outcomes Prevention Evaluation (HOPE) Investigators. Reduction of cardiovascular risk by regression of electrocardiographic markers of left ventricular hypertrophy by the angiotensin-converting enzyme inhibitor ramipril. Circulation 2001;104:1615-1621. 
16. Fagard RH, Staessen JA, Thijs L, Celis H, Birkenhager WH, Bulpitt CJ, de Leeuw PW, Leonetti G, Sarti C, Tuomilehto J, Webster J, Yodfat Y, Systolic Hypertension in Europe (Syst-Eur) Trial Investigators. Prognostic significance of electrocardiographic voltages and their serial changes in elderly with systolic hypertension. Hypertension 2004;44:459-464.

17. Okin PM, Devereux RB, Jern S, Kjeldsen SE, Julius S, Nieminen MS, Snapinn S, Harris KE, Aurup P, Edelman JM, Wedel H, Lindholm LH, Dahlöf B. Regression of electrocardiographic left ventricular hypertrophy during antihypertensive treatment and prediction of major cardiovascular events: The LIFE Study. JAMA 2004; 292:2343-2349

18. Okin PM, Devereux RB, Harris KE, Jern S, Kjeldsen SE, Julius S, Edelman JM, Dahlöf B, for the LIFE Study Investigators. Reduction of electrocardiographic left ventricular hypertrophy is associated with decreased heart failure hospitalization in hypertensive patients. Ann Intern Med 2007;147:311-319.

19. Okin PM, Oikarinen L, Viitasalo M, Toivonen L, Kjeldsen SE, Nieminen MS, Edelman JM, Dahlöf B, Devereux RB. Prognostic value of changes in the electrocardiographic strain pattern during antihypertensive treatment: the LIFE study. Circulation 2009;119:1183-1891.

20. Okin PM, Devereux RB, Harris KE, Kjeldsen SE, Edelman JM, Dahlöf B. Incidence of heart failure in relation to QRS duration during antihypertensive therapy: the LIFE study. J Hypertens 2009;27:2271-2277.

21. Dahlöf B, Devereux RB, Kjeldsen SE, Julius S, Beevers G, de Faire U, Fyhrquist F, Ibsen H, Kristiansson K, Lederballe-Pedersen O, Lindholm LH, Nieminen MS, Omvik P, Oparil S, Wedel H, for the LIFE study group. Cardiovascular morbidity and mortality in the Losartan Intervention for Endpoint reduction in hypertension study (LIFE): a randomised trial against atenolol. Lancet 2002;359:995-1003.

22. Dahlöf B, Devereux R, de Faire U, Fyhrquist F, Hedner $T$, Ibsen $H$, Julius $S$, Kjeldsen S, Kristiansson K, Lederballe-Pedersen O, Lindholm LH, Nieminen MS, Omvik P, Oparil S, Wedel H, for the LIFE study group. The Losartan Intervention
For Endpoint Reduction (LIFE) in Hypertension Study: rationale, design, and methods. Am J Hypertens 1997; 10:705-713.

23. Okin PM, Roman MJ, Devereux RB, Kligfield P. Electrocardiographic identification of increased left ventricular mass by simple voltage-duration products. J Am Coll Cardiol 1995;25:417-423.

24. Kannel WB, D'Agostino RB, Silbershatz H, Belanger AJ, Wilson PWF, Levy D. Profile for estimating risk of heart failure. Arch Intern Med 1999;159:1197-1204.

25. Palmieri V, Okin PM, Bella JN, Wachtell K, Oikarinen L, Gerdts E, Boman K, Nieminen MS, Dahlöf B, Devereux RB. Electrocardiographic strain pattern and left ventricular diastolic function in hypertensive patients with left ventricular hypertrophy: the LIFE Study. J Hypertension 2006;24:2079-2084.

26. Russo C, Jin Z, Homma S, Rundek T, Elkind MSV, Sacco RL, Di Tullio MR. Effect of diabetes and hypertension on left ventricular diastolic function in a high-risk population without evidence of heart disease. Eur J Heart Fail 2010;12:454-461.

27. Rembert JC, Kleinman LH, Fedor JM, Wechsler AS, Greenfield JC Jr. Myocardial blood flow distribution in concentric left ventricular hypertrophy. J Clin Invest 1978;62:379-386.

28. O'Keefe JH, Owen RM, Bove AA. Influence of left ventricular mass on coronary artery cross-sectional area. Am J Cardiol 1987;59:1395-1397.

29. Anderson HV, Stokes MJ, Leon M, Abu-Halawa SA, Stuart Y, Kirkeeide RL. Coronary flow velocity in related to lumen area and regional left ventricular mass. Circulation 2000;102:48-54.

30. Okin PM, Roman MJ, Lee ET, Galloway JM, Howard BV, Devereux RB. Combined echocardiographic left ventricular hypertrophy and electrocardiographic ST depression improve prediction of mortality in American Indians: The Strong Heart Study. Hypertension 2004;43:769-774.

31. Dahlstrom U, Hakansson J, Swedberg K, Waldenstrom A. Adequacy of diagnosis and treatment of chronic heart failure in primary health care in Sweden. Eur J Heart Fail 2009;11:92-98. 